\title{
Silica-encapsulated DNA tracers for measuring aerosol distribution dynamics in real-world settings
}

\section{Journal Article}

\section{Author(s):}

Luescher, Anne M.; Koch, Julian; Stark, Wendelin J.; Grass, Robert N.

Publication date:

2022-01

Permanent link:

https://doi.org/10.3929/ethz-b-000519221

\section{Rights / license:}

Creative Commons Attribution-NonCommercial-NoDerivatives 4.0 International

\section{Originally published in:}

Indoor Air 32(1), https://doi.org/10.1111/ina.12945 


\title{
Silica-encapsulated DNA tracers for measuring aerosol distribution dynamics in real-world settings
}

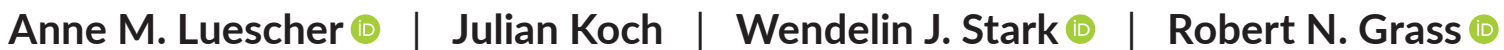

Institute for Chemical and Bioengineering, ETH Zurich, Zurich, Switzerland

\section{Correspondence}

Robert N. Grass, Institute for Chemical and Bioengineering, ETH Zurich, VladimirPrelog-Weg 1, 8093 Zurich, Switzerland. Email: robert.grass@chem.ethz.ch

\section{Funding information}

This work was financially supported by ETH Zürich

\begin{abstract}
Aerosolized particles play a significant role in human health and environmental risk management. The global importance of aerosol-related hazards, such as the circulation of pathogens and high levels of air pollutants, have led to a surging demand for suitable surrogate tracers to investigate the complex dynamics of airborne particles in real-world scenarios. In this study, we propose a novel approach using silica particles with encapsulated DNA (SPED) as a tracing agent for measuring aerosol distribution indoors. In a series of experiments with a portable setup, SPED were successfully aerosolized, recaptured, and quantified using quantitative polymerase chain reaction (qPCR). Position dependency and ventilation effects within a confined space could be shown in a quantitative fashion achieving detection limits below $0.1 \mathrm{ng}$ particles per $\mathrm{m}^{3}$ of sampled air. In conclusion, SPED show promise for a flexible, cost-effective, and low-impact characterization of aerosol dynamics in a wide range of settings.

\section{KEYWORDS}

aerosol, DNA, nanoparticles, silica, tracing, ventilation
\end{abstract}

\section{1 | INTRODUCTION}

Aerosol dynamics are an important factor when assessing the circulation of hazardous pollutants and pathogens with regard to human health and the environment. Viable bioaerosols are a wellknown cause for many infectious diseases such as tuberculosis, ${ }^{1}$ measles, ${ }^{2}$ Legionnaire's disease, ${ }^{3}$ influenza, ${ }^{4}$ gastroenteritis, ${ }^{5}$ and SARS-CoV- $1^{6}$ and SARS-CoV-2. ${ }^{7-10}$ With the COVID-19 pandemic spreading globally, the importance of understanding the mechanisms of aerosol spreading has perhaps become more evident than ever, and discussions surrounding the topic have reached the mainstream. Specifically, the assessment and characterization of aerosol distribution properties within specific indoor spaces such as lecture halls, office spaces, hospitals, public transport vehicles, or event venues are of high interest with regard to public and occupational health.
Many of the existing approaches to assess indoor environments regarding aerosol dynamics rely on computational models. However, such models are based on the preexisting understanding of fluid dynamics and prone to numerical error, ${ }^{11}$ while also depending on data for setting realistic parameters. ${ }^{12}$ Therefore, predicting real-world behavior in complex, non-controlled environments is computationally challenging. For those reasons, physical tracing is still a vital field to assess aerosol-related properties in real-world settings to help validate and complement model-based studies.

Table 1 shows a list of studies reporting tracing methods to characterize (bio-)aerosol distribution indoors. Carbon dioxide, for example, is a commonly used tracer gas, applied either alone or in combination with other tracers, and in conjunction with one or more $\mathrm{CO}_{2}$ detectors. For example, Knibbs et al. ${ }^{13}$ employed $\mathrm{CO}_{2}$ to assess the effect of ventilation rates in various room settings, using the results to model virus-specific infection risks. While $\mathrm{CO}_{2}$ is widely accessible,

This is an open access article under the terms of the Creative Commons Attribution-NonCommercial-NoDerivs License, which permits use and distribution in any medium, provided the original work is properly cited, the use is non-commercial and no modifications or adaptations are made.

(c) 2021 The Authors. Indoor Air published by John Wiley \& Sons Ltd. 
non-toxic (in low concentrations), easily detected, and self-clearing, it is also naturally present in ambient air. Subtle effects may therefore be harder to detect, and relatively high working concentrations are needed. Moreover, aerosol dynamics are complex and not necessarily approximated accurately by a non-particulate tracer gas.

Schade et al. ${ }^{14}$ therefore combined $\mathrm{CO}_{2}$ with an aerosol tracer to characterize distribution in a large concert hall. Their combinatorial approach has the advantage of monitoring aerosol droplets with temporal and spatial resolution, with the limitation that the particle counters used for detection are not specific to the tracer aerosols, and the resolution of detection is only in the $\mu \mathrm{g} / \mathrm{m}^{3}$ range.

Another approach, by Pyankov et al., ${ }^{15}$ uses influenza A virus as a tracer and a personal sampler for detection. However, they focus on introducing a new method of detection rather than a routine tracer entity for room characterization. Any approach using live viruses is not routinely feasible in a real-world setting as it requires high safety precautions, well-trained personnel, and extended experimental preparation time.

Further physical tracers, ${ }^{16-22}$ typically used outdoors and for environmental tracing, exist, but they, too, face challenges related to either environmental background concentrations, hazard, and toxicity or non-specificity of the detection method.

None of the reviewed tracing methods are suitable for complex multi-tracing or offer an extensive platform for flexible tuning of properties. There is still an unmet need for additional tracing methods allowing for direct and reliable experimental real-world characterization of indoor spaces regarding (bio-)aerosol distribution. Hence, novel tracing materials that are cost-effective, non-toxic, and can be detected with a high sensitivity and specificity in a broad range of scenarios would be a valuable addition to existing tools.

We propose a new approach using aerosolized silica particles with encapsulated DNA (SPED) to analyze aerosol dynamics. These submicron particles stand out in their ease of synthesis, durability, and quantitative analysis with a low detection limit, as described by

\section{Practical Implications}

For the first time, silica particles with encapsulated DNA were used to characterize a confined indoor space regarding position- and ventilation-dependent effects of aerosol distribution. The method described here introduces SPED as a novel, non-toxic, low-impact, cost-effective, and easyto-use aerosol tracing platform that can be used to examine real-world environments. The mobile setup presented here as a proof of concept shows that SPED can be aerosolized and recaptured, followed by highly sensitive quantitative barcode-specific PCR analysis. The results revealed that this tracing method can detect position-dependent differences in exposure and ventilation effects influencing distribution dynamics. In the future, SPED could be engineered to exhibit custom-designed properties and be employed within a wide range of setups and high-capacity multi-tracing combinations.

Paunescu et al. ${ }^{23}$ Silica is recognized as 'safe' by the FDA and used as food additive as well as in medicine. ${ }^{24} \mathrm{~A}$ previous study shows no observable adverse effects of SPED in standard ecotoxicity assays $^{25}$ and exposure of rats to airborne silica nanoparticles in concentrations up to $86 \mathrm{mg} / \mathrm{m}^{3}$ over several days did not lead to any toxicological symptoms. ${ }^{26}$ As previously shown, the employed sol-gel synthesis leads to a uniform size distribution with each particle carrying a comparable number of DNA sequences. ${ }^{23,27}$ The encapsulated artificial DNA, or 'DNA barcode', is not present in the environment and can be detected with an extraordinarily high selectivity and sensitivity using real-time quantitative polymerase chain reaction (qPCR). This powerful detection method is known for its use in diagnostics to identify various pathogens, for example in food, ${ }^{28}$ water, ${ }^{29}$ and also aerosols. ${ }^{15,30,31}$ Likewise, SPED are

TAB LE 1 Literature overview listing aerosol tracing methods for room characterization

\begin{tabular}{|c|c|c|c|c|c|}
\hline Method & Tracer type & Tracer size & $\begin{array}{l}\text { Means of aerosol } \\
\text { generation/ distribution }\end{array}$ & Means of collection & $\begin{array}{l}\text { Method of } \\
\text { quantification }\end{array}$ \\
\hline Schade et al. ${ }^{14}$ & $\begin{array}{l}\mathrm{DEHS}^{\mathrm{a}} \text { (in conjunction } \\
\text { with } \mathrm{CO}_{2} \text { ) }\end{array}$ & $\begin{array}{c}300 \mathrm{~nm} \text { (maximum of } \\
\text { size distribution) }\end{array}$ & $\begin{array}{l}\text { Aerosol generator with } \\
\text { integrated pump }\end{array}$ & $\begin{array}{l}\text { Handheld particle } \\
\text { counters }\end{array}$ & $\begin{array}{l}\text { Optical light scattering } \\
\text { (particle counter) }\end{array}$ \\
\hline Pyankov et al. ${ }^{15}$ & Influenza A virus & $\mathrm{n} / \mathrm{a}$ & 3-jet Collison nebulizer & Bioaerosol sampler & PCR \\
\hline LUQAS study $^{73}$ & Artificial saliva & $\mathrm{n} / \mathrm{a}$ & Particle generator ${ }^{c}$ & No collection & LDA/PDA and PIV \\
\hline Van Rijn et al. ${ }^{74}$ & Glycerol/ethanol & $\begin{array}{c}\text { Same size distribution } \\
\text { as cough droplets }\end{array}$ & $\begin{array}{l}\text { Specially designed spray } \\
\text { nozzle }\end{array}$ & No collection & $\begin{array}{l}\text { SprayScan }{ }^{\circledR} \text { laser } \\
\text { sheet }\end{array}$ \\
\hline Knibbs et al. & $\mathrm{CO}_{2}$ & No droplets & No aerosols & No collection & CA-10 $\mathrm{CO}_{2}$ analyzer \\
\hline This work & $\begin{array}{l}\text { Silica-encapsulated } \\
\text { DNA }\end{array}$ & Ca. $150 \mathrm{~nm}^{\mathrm{d}}$ & Airbrush gun & $\begin{array}{l}\text { BioSampler } \\
\text { Impinger }\end{array}$ & PCR \\
\hline
\end{tabular}

${ }^{a}$ Di-ethylhexyl-sebacate.

${ }^{b}$ For the devices used in the study, no lower limit of detection is available. For the Fidas ${ }^{\circledR}$ Frog, used for position-dependent counting, a measuring range of $0-20000000 \mathrm{p} / \mathrm{L}$ is indicated by the manufacturer. For the PCE devices used for time-resolved sampling, the resolution is $1 \mu \mathrm{g} / \mathrm{m}^{3}$ according to the product information, meaning the limit of detection would be equal to that, or higher.

cNot further specified, but image provided in study.

${ }^{\mathrm{d}}$ Mean of hydrodynamic size distribution of tracer agent in suspension. 
already established as tracers for liquids and surfaces and have been used to characterize aquifers, ${ }^{32}$ assess pesticide drift, ${ }^{33}$ track and trace commodities, ${ }^{34,35}$ and observe trophic interactions within food webs. ${ }^{36}$ Moreover, they have been employed as surrogate tracers for bacteria in a hospital environment. ${ }^{37}$ Similarly, bacteriophages, C. difficile spores, and cauliflower mosaic DNA have been employed for surface tracing in various settings, sometimes in conjunction or compared with fluorescent markers. ${ }^{38-43}$ The DNA sequences are unique identifiers, offering a great advantage over other methods by allowing for specific detection. In the case of SPED, the sequences are synthetic, not bound to an organism, can be changed at will and are more robust through silica encapsulation. Since even a sequence length of just 60-100 nucleotides offers trillions of potential barcodes, a system with nearly unlimited multi-tracing capabilities is conceivable. Thus, the advantages of highly sensitive PCR detection can be implemented without the need for tracing organisms.

In this study, SPED are dispersed as aerosols and recollected using commercial biosampler impingers, which offer a proven method to capture aerosols. ${ }^{44-46}$ The DNA is then released from its silica protection and quantitatively analyzed. The overall principle is summarized in Figure 1. Two batches of SPED, S1 and S2, were used, which differ in the sequence of their DNA barcode. Working with these unique identifiers has the advantage that they enable a wide variety of experiments, largely eliminating contamination between experiments and permitting scenarios such as simultaneous multi-source sampling.

\section{2 | MATERIALS AND METHODS}

\section{1 | Synthesis of SPED}

Silica particles with encapsulated DNA synthesis (S1 and S2) was performed in adaption of Paunescu et al. ${ }^{23}$ and characterized regarding DNA load, size, and shape. For DNA encapsulation, $4 \times 4 \mathrm{ml}$ of silica nanoparticles (110 nm, $50 \mathrm{mg} / \mathrm{ml}$ in isopropanol; Pinfire) per batch were surface-functionalized in 4 separate falcon tubes by adding $40 \mu \mathrm{g}$ of $\mathrm{N}$-trimethoxysilylpropyl-N,N,N- trimethylammonium chloride (TMAPS) (50\% wt in methanol; abcr) followed by $12 \mathrm{~h}$ of stirring at 900 rotations per minute (rpm) at room temperature. For DNA adsorption to the surface, a $2 \mathrm{ml}$ batch of $150 \mathrm{ng} / \mu \mathrm{l}$ corresponding annealed DNA (sequences see Table 2; Microsynth AG) was added to $200 \mathrm{ml}$ ultrapure water (mQ; type $1,18.2 \mathrm{M} \Omega \cdot \mathrm{cm}$ at $24^{\circ} \mathrm{C}$, Milli- $\mathrm{Q}^{\circledR}$; Merck). $0.4 \mathrm{~g}$ of the functionalized particles were added to the DNA solution and shaken for $10 \mathrm{~s}$. Subsequently, $4 \mu \mathrm{l}$ TMAPS were added, then the mix was shaken and sonicated for $20 \mathrm{~s}$. Next, $62.5 \mu \mathrm{l}$ of tetraethyl orthosilicate (TEOS) ( $\geq 99.0 \%$; Sigma-Aldrich) were added, followed by $5 \mathrm{~h}$ of shaking at $600 \mathrm{rpm}$ on a mixer (Vibramax 100; Heidolph) with a universal clamping attachment (VX 8; IKA). In a further step, $10 \mathrm{ml}$ isopropanol and $5.9 \mathrm{ml}$ TEOS were mixed with $484.1 \mathrm{ml} \mathrm{mQ}$ water and combined with the previous mixture. The batch was again stirred at $600 \mathrm{rpm}$ for 4 days, before washing twice with water.

\section{2 | SPED characterization}

DNA load was determined by photospectrometric measurement of DNA concentration in solution before and after encapsulation (NanoDrop 2000c; Thermo Fisher Scientific). Particle size distributions of SPED in suspension (prepared in $\mathrm{mQ}$ water at $\sim 2 \mathrm{mg}$ / $\mathrm{ml}$ ) were measured using an analytical photocentrifuge (dispersion analyzer LUMiSizer, light source $470 \mathrm{~nm}$; LUM $\mathrm{GmbH}$,). Transmission profiles were recorded for $2 \mathrm{~h}$ in time intervals of $5 \mathrm{~s}$, at a rotational speed of 3000-4000 rpm. Statistical data analysis was performed by SEPView ${ }^{\circledR}$ software (LUM GmbH). Scanning electron microscopy (SEM) was performed on NovaNanoSEM450 device (Field Electron and Ion Company) with samples loaded on a TEM grid.

\begin{tabular}{|c|c|c|c|c|c|}
\hline $\begin{array}{l}\text { Time-/location- } \\
\text { resolved results }\end{array}$ & Lower limit of detection & $\begin{array}{l}\text { Specificity } \\
\text { for tracer }\end{array}$ & $\begin{array}{l}\text { Tracer occurring naturally in } \\
\text { envirionment }\end{array}$ & $\begin{array}{l}\text { Toxicity/ infectious-ness } \\
\text { at working conc. }\end{array}$ & $\begin{array}{l}\text { Multi-tracing } \\
\text { possible }\end{array}$ \\
\hline Yes/yes & $\begin{array}{l}1 \mu \mathrm{g} / \mathrm{m}^{3} \text { resolution in time- } \\
\text { resolved measurement }\end{array}$ & No & No $(\mathrm{DEHS}) /$ yes $\left(\mathrm{CO}_{2}\right)$ & No & No \\
\hline No/no & $\mathrm{n} / \mathrm{a}$ & Yes & Yes & Yes & No \\
\hline Yes/yes & $\mathrm{n} / \mathrm{a}$ & No & No & No & No \\
\hline Yes/no & $\mathrm{n} / \mathrm{a}$ & Yes & Yes & No & No \\
\hline Yes/yes & $<0.1 \mathrm{ng} / \mathrm{m}^{3}$ & Yes & No & No & Yes \\
\hline
\end{tabular}




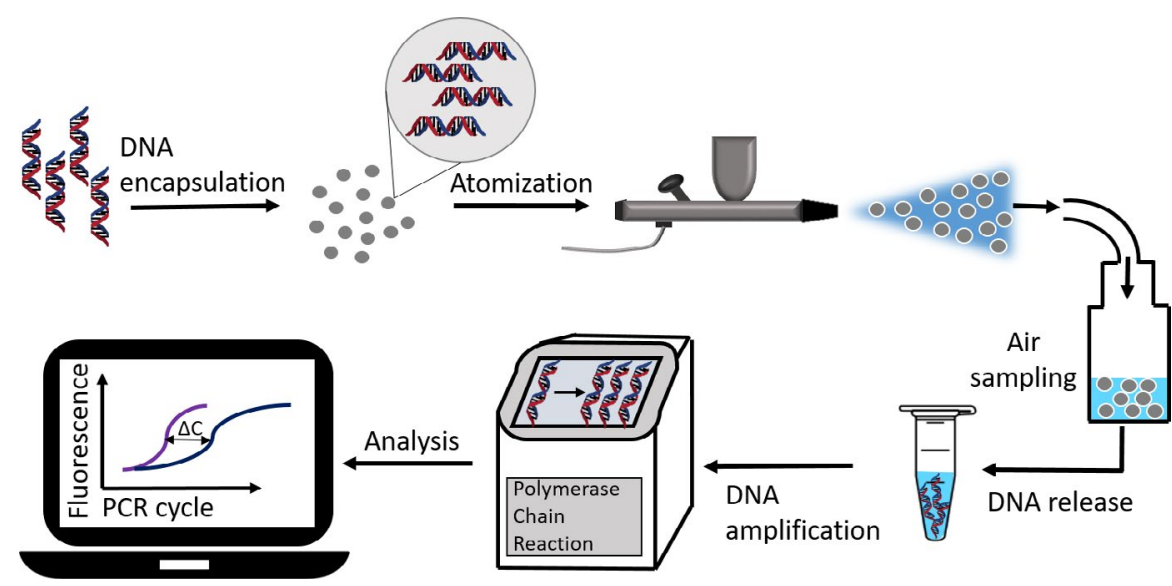

FIGURE 1 Schematic description of the tracing method using SPED. DNA is encapsulated in silica particles to form SPED, which are then aerosolized using an airbrush gun. The air is sampled using glass biosamplers. DNA is released from the collected SPED and quantified by qPCR

TABLE 2 DNA sequences encapsulated in silica for SPED synthesis

\begin{tabular}{ll} 
Name & Sequence \\
\hline S1 forward & TATGCGCCTTTATACTCTTATAGGTATCCTGTTGCTGGCACTTTTTTCTAGCAAAGTCTTCTCCT \\
\hline S1 reverse & AGGAGAAGACTTTGCTAGAAAAAAGTGCCAGCAACAGGATACCTATAAGAGTATAAAGGCGCATA \\
S2 forward & TAGCTCGTTCATAGAATCACTTCGCCGTACTCAACGTAGTGGTTTTTGTTTAGCTCAAACAGGTT \\
S2 reverse & AACCTGTTTGAGCTAAACAAAAACCACTACGTTGAGTACGGCGAAGTGATTCTATGAACGAGCTA \\
\hline
\end{tabular}

\subsection{Aerosolization and droplet characterization}

The aerosol experiments were performed in a $277 \mathrm{~m}^{3}$ laboratory running at a ventilation throughput of $1840 \mathrm{~m}^{3} / \mathrm{h}$. A technical layout of the room can be found in the Appendix S1, Figure S2d. SPEDcontaining aerosols were generated by a commercial airbrush gun with a $0.35 \mathrm{~mm}$ nozzle (type AFC-101A; Conrad Electronic) using an air pressure of 1 bar, mounted to a height of $1.6 \mathrm{~m}$ on a mobile stand. Phase Doppler anemometry was used to characterize droplet size distribution as created by the airbrush gun used for aerosol generation. PDA was measured on a setup using a Phase Doppler anemometer (TSI Inc.) operated with a water-cooled $5 \mathrm{~W}$ argon-ion laser (Innova 70, LA-70-5), generating a green and blue laser beam with a wavelength of 514.4 and $488 \mathrm{~nm}$, respectively. To measure droplet size distribution, pure water was used, at a flow rate of ca. $2 \mathrm{ml} / \mathrm{min}$. The point of measurement was $2 \mathrm{~cm}$ frontal to the nozzle.

For each sampling, $5 \mathrm{ml}$ of a $0.2 \mathrm{mg} / \mathrm{ml}$ aqueous suspension of the respective SPED species were nebulized over the course of approx. $1 \mathrm{~min}$. For the treatment and wash protocol of SPED before dispersion, refer to the Appendix S1, Section S1.4.

\section{4 | Aerosol capture}

For aerosol capture, biosamplers, also called flow impingers (Aquaria SRL and SKC Ltd), were filled with $20 \mathrm{ml}$ of ultrapure water and equally mounted to a height of $1.6 \mathrm{~m}$. For photographs and descriptions of the different components refer to the Appendix S1, Figures S3 and S4. Before aerosol dispersion, zero sampling was performed, which consisted of sampling the empty room using the same setup and conditions.
Air samplers were used in combination with $40 \mathrm{l} / \mathrm{min}$ piston vacuum pumps (Ningbo Nuolin Mechatronics Co Ltd), whereby the airflow rate was reduced to $12.5 \mathrm{l} / \mathrm{min}$ using needle valves. If not indicated otherwise, sampling time was $2 \mathrm{~h}$ post-dispersion. For timeresolved experiments, the pumps were briefly stopped at given time points, each time removing $200 \mu$ of the respective capturing liquid from the samples for analysis.

\subsection{Quantitative PCR}

Immediately after sampling, the collection liquid from each flow impinger was transferred into a $50 \mathrm{ml}$ falcon tube and sonicated for $10 \mathrm{~min}$ in an ultrasound bath (model Sonorex Digitec DT $31 \mathrm{H}$; Bandelin) at room temperature. A total of $200 \mu \mathrm{l}$ were used for further processing and treated with $4 \mu$ l buffered oxide etch, consisting of 0.03 wt\% ammonium hydrogen difluoride $\left(\mathrm{NH}_{4} \mathrm{FHF}\right.$, pure; Merck) and 0.02 wt\% ammonium fluoride $\left(\mathrm{NH}_{4} \mathrm{~F}\right.$, puriss.; Sigma-Aldrich). After adding the etching reagent, the mix was vortexed and sonicated again. For the subsequent polymerase chain reaction, $5 \mu \mathrm{l}$ of the broken-down SPED solution were mixed with $10 \mu \mathrm{l}$ of KAPA SYBR FAST qPCR master mix universal (2x; Kapa Biosystems), $1 \mu \mathrm{l}$ of each primer solution, and $3 \mu \mathrm{l}$ of PCR-grade water (type 1 , $18.2 \mathrm{M} \Omega \cdot \mathrm{cm}$ at $24^{\circ} \mathrm{C}$, Milli-Q ${ }^{\circledR}$; Merck). Primer sequences (see Table 3) were ordered in dry state from Microsynth AG and dissolved in PCR-grade water to a working concentration of $10 \mu \mathrm{M}$. Samples were run in technical triplicates on a LightCycler ${ }^{\circledR} 96$ instrument (Roche Molecular Systems). The qPCR program consisted of a preincubation step $\left(240 \mathrm{~s}, 95^{\circ} \mathrm{C}\right)$ followed by 40 cycles of 3-step amplification $\left(2 \mathrm{~s}, 95^{\circ} \mathrm{C} ; 12 \mathrm{~s}, 60^{\circ} \mathrm{C} ; 4 \mathrm{~s}, 72^{\circ} \mathrm{C}\right)$. Cycle values were assigned automatically from qPCR fluorescence curves by the LightCycler ${ }^{\circledR}$ 
96 SW 1.1 analysis program (Roche Molecular Systems) and conversed to concentrations based on previously measured standard curves. For a more detailed description of the calculations and determination of experimental detection limits refer to Appendix S1, Sections S1.4-5 (Table 3).

\section{6 | Fog experiment}

For visualization of air and ventilation dynamics, fog was generated by a commercial fog machine (Model Rage 600I; BeamZ), used in conjunction with the liquid provided with the device (BeamZ fog fluid $1 \mathrm{~L}$ High-Density). The fog was dispersed according to instructions by the manufacturer from the same point of origin as the SPED. Per experiment, one load was dispersed, corresponding to 20-30 s of continuous operation. Qualitative analysis was performed by eye and documented in images and on video S1.

\section{3 | RESULTS AND DISCUSSION}

Characterization of the two SPED species (S1 and S2) used for the following tracing studies revealed a DNA load of $23 \mu \mathrm{g}$ and $26 \mu \mathrm{g}$ dsDNA/mg for S1 and S2 particles, respectively. The median hydrodynamic size was determined to be $133.5 \mathrm{~nm}$ for S1 and $160.6 \mathrm{~nm}$ for $\mathrm{S} 2$, as shown in Figure 2B. This is further confirmed by electron microscopy (Figure 2A), which shows the spherical shape and homogenous size distribution of the particles. The selected core particle

TABLE 3 Primer sequences used for $\mathrm{qPCR}$

\begin{tabular}{ll}
\hline Primer name & Sequence \\
\hline S1 forward & ATGCGCCTTTATACTCTTA \\
S1 reverse & GGAGAAGACTTTGCTAGAA \\
S2 forward & AGCTCGTTCATAGAATCAC \\
\hline S2 reverse & ACCTGTTTGAGCTAAACAA \\
\hline
\end{tabular}

size of $110 \mathrm{~nm}$ is similar to viruses like adenovirus, ${ }^{47}$ influenza $A,{ }^{48}$ or SARS-CoV- $2,{ }^{49}$ all ranging between 90 and $120 \mathrm{~nm}$ in size.

In addition to the hydrodynamic diameter of SPED in suspension, the droplet size generated by the airbrush gun was determined using phase Doppler anemometry (PDA), the results of which are shown in Figure $2 \mathrm{C}$. The measured particle count distribution yielded a droplet size of $10.8 \pm 4.4 \mu \mathrm{m}$. There is abundant literature characterizing size distributions of droplets as created by the human respiratory tract. $^{50-62}$ The reported average sizes range from submicrometer diameters up to several hundred micrometers. The size differs between types of respiratory action, i.e. regular breath, speech, coughing, or sneezing, and also greatly varies depending on study design variables, such as point of measurement, means of collection and detection, and statistical methods. In a study employing an optical detection method comparable to PDA to measure respiratory droplets in immediate proximity to the source, a median droplet size of $12.3 \mu \mathrm{m}$ was found for coughing, ${ }^{61}$ which is a similar size range as generated by the airbrush gun.

Further, it is important to note that the droplet size distribution and the particle size distribution are two separate entities. The droplet size distribution is the factor determining which fraction of the dispersed particles become airborne after the carrier liquid evaporates, as described in a model developed by Wells et al. ${ }^{63}$ This so-called Wells falling evaporation curve was later refined by Xie et al., ${ }^{64}$ showing that water-based droplets below a size of $60 \mu \mathrm{m}$ evaporate quickly under standard indoor conditions and can remain suspended in the air for longer periods of time. Considering this, the entities collected are not primarily the droplets as dispersed but the aerosolized droplet nuclei. This is schematically shown in Figure 3. This phenomenon, too, is multifactorial and determined by interdependent parameters such as temperature, humidity, and the concentration of particulate matter suspended in the air. Generating an experimental setup that mimics human respiration is therefore not trivial and was not a primary focus of this study. Nevertheless, the droplet size distribution created by the airbrush gun falls within the previously reported range for respiratory droplets and SPED have a similar hydrodynamic volume as a typical virus as base properties

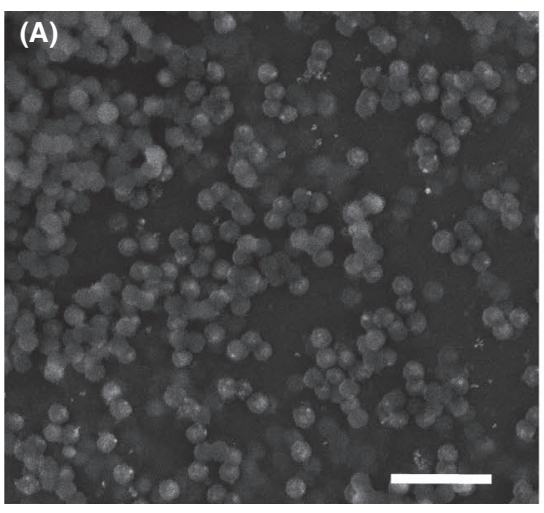

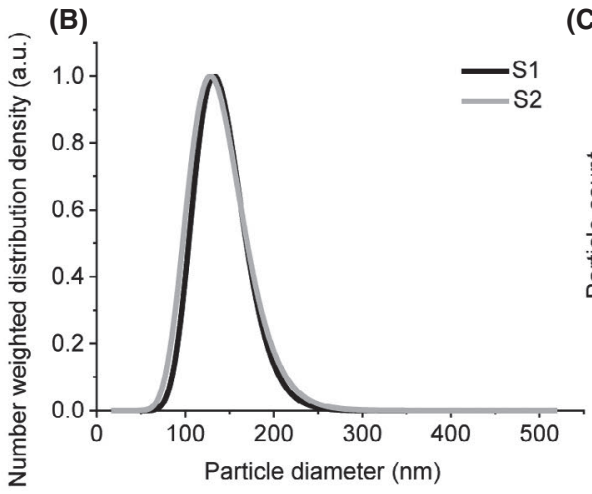

(B)
(C)

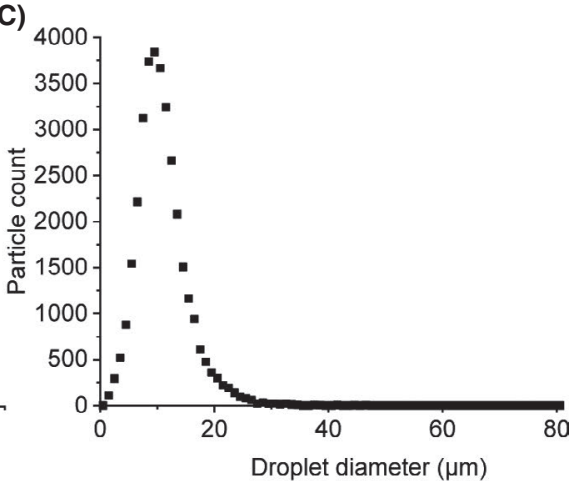

FIGURE 2 (A) Scanning electron microscopy (SEM) image of SPED species S2. Scale bar is $500 \mathrm{~nm}$. (B) Hydrodynamic size distribution of two batches of SPED (S1 and S2) by analytical photocentrifugation. For S1, the median is at $133.5 \mathrm{~nm}$, for S2 at $160.6 \mathrm{~nm}$. (C) Diameter of droplets generated by the airbrush gun, as measured by phase Doppler anemometry. The arithmetic mean droplet size is $10.8 \pm 4.4 \mu \mathrm{m}$ 
for the following measurements. Figure 4A shows a summary of the setting used to investigate and quantify the relative distribution of SPED aerosols indoors. $5 \mathrm{ml}$ of a $0.2 \mathrm{mg} / \mathrm{ml}$ particle suspension were dispersed over the time course of ca. $1 \mathrm{~min}$ in a $277 \mathrm{~m}^{3}$ laboratory, running at a ventilation output of $1840 \mathrm{~m}^{3} / \mathrm{h}$. This corresponds to roughly 6.6 air changes per hour $(\mathrm{ACH})$ or roughly one air changes every $10 \mathrm{~min}$. For aerosol capture, up to 5 flow impingers were mounted with the inlets at a height of $1.6 \mathrm{~m}$. This height was chosen because it is similar to the level of the nose of an average worker in the laboratory. A graphic depicting the location of the samplers within the test space is shown in Figure 4B. For aerosol capture, each flow impinger was connected to a pump aspirating $12.5 \mathrm{I} / \mathrm{min}$ of ambient air, which is close to a human's minute ventilation for a low-level activity, such as driving a car. ${ }^{65}$ This enables sampling of a significant amount of air over time, while still detecting local exposure rather than sampling the room globally. Through the focused airflow, aerosols are trapped in the collection water, which can directly be used for further processing and subsequent PCR-analysis. The setup is mobile and only requires electricity from regular sockets and a small-compressed air source for the airbrush gun. A batterypowered version of the same setup would also be feasible.

As a pilot test, a time-resolved experiment was conducted. For this experiment, two flow impingers were used, mounted $2 \mathrm{~m}$ and $6 \mathrm{~m}$ frontal to the origin of aerosol flow, respectively, and the test laboratory ran at regular ventilation output. $1 \mathrm{mg}$ of SPED 1 was dispersed, and during a continuous sampling time of $120 \mathrm{~min}$, $200 \mu \mathrm{l}$ samples were removed from the initial $20 \mathrm{ml}$ solution at 14 time points and analyzed separately for their SPED concentration. Figure $5 \mathrm{~A}$ shows the integrated aerosol levels measured in the two impingers over time. The first measurement, at $t=0$, was taken before dispersion and is thus the experimental negative control, marking the minimal limit of detection (MLD) of $4.5 \cdot 10^{-9} \mathrm{mg} / \mathrm{ml}$ in the sampling solution for this experiment. Assuming a conservative physical collection efficiency for the impingers of $10 \%$, as estimated from literature data, ${ }^{66-68}$ this corresponds to a particle concentration detection limit of $6 \cdot 10^{-2} \mathrm{ng} / \mathrm{m}^{3}$ of sampled air. Comparing this value to commercial monitoring systems for inorganic particulate matter $2.5\left(\mathrm{PM}_{2.5}\right)^{69,70}$ the MLD of the present method is at least one order of magnitude lower. More information on the impinger efficiency, concentration measurements, and how detection limits were determined can be found in the Appendix S1, Section S1.5.

Following the aerosol generation, the amount of SPED collected rises sharply in both impingers, before reaching a plateau load in the range of $3 \cdot 10^{-4} \mathrm{mg}$ and $2 \cdot 10^{-4} \mathrm{mg}$, respectively. At position 1 , the maximum is reached within the first measurement increment after $3 \mathrm{~min}$, whereas at a distance of $6 \mathrm{~m}$, there is a distinguishable saturation curve reaching the plateau after an estimated 10-20 min, attributing to the fact that the aerosols reach the second sampling point with a delay due to further traveling distance. This positiondependent effect is also reflected in the total collection loads, which correspond to estimated position-specific dosages of $0.35 \%$ and $0.2 \%$ of the total amount of released SPED. Throughout the measurement time, there are some fluctuations; however, these deviations are within the expected range for PCR reactions, as discussed further below.

To further investigate position dependency, the total load over 120 min was measured under otherwise equal sampling conditions. In addition to the two impingers used in the previous experiments,
(A)

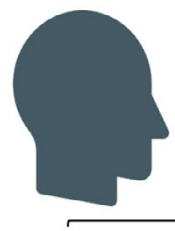

\section{Suspended evaporating droplets}

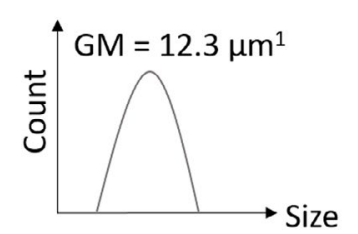

$\rightarrow$ time

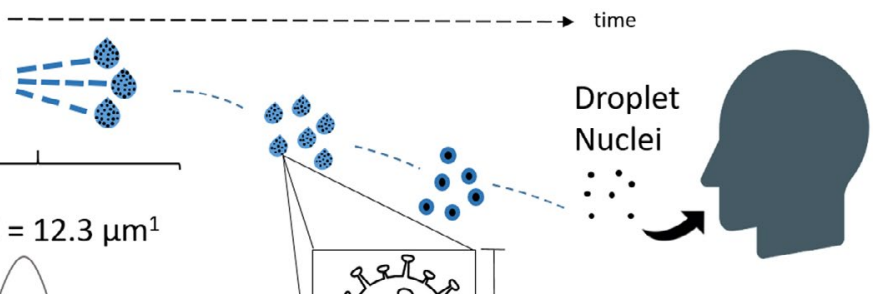
$\begin{array}{lll}90005 & \text { SARS COV 2: } \\ 09000-140 \mathrm{~nm}^{3}\end{array}$ कित्रु

$1.8 \mathrm{~L} / \mathrm{min}^{2}$

(B)

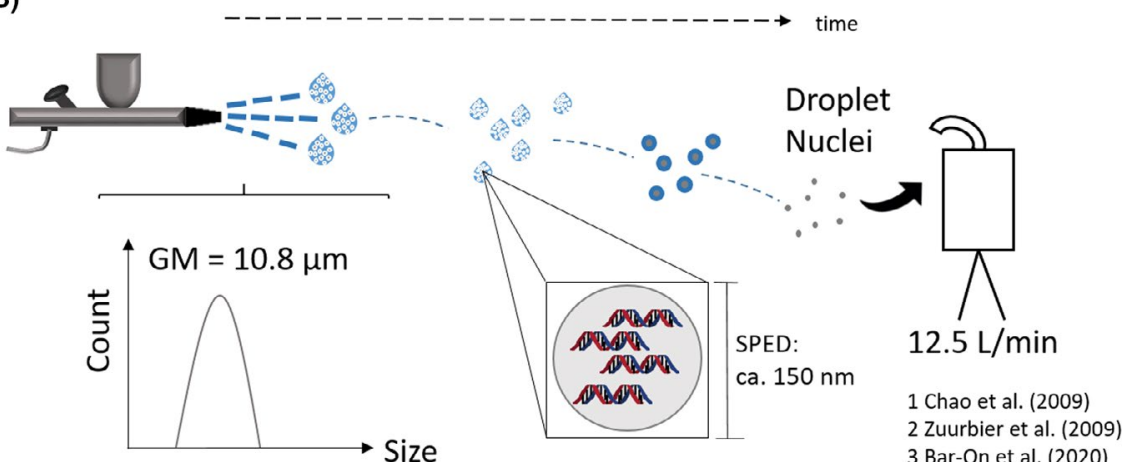

FIGURE 3 Schematic representation of exposure scenarios with evaporating droplets, comparing $(A)$ virus-carrying aerosols as produced by a human cough with (B) the laboratory setup used in this study 
FIGURE 4 (A) Schematic

representation of room characterization experiments. SPED are dispersed in an indoor environment, recollected using one or several sampling devices and analyzed using quantitative PCR. (B) Room layout of the laboratory used for the experiments, schematically showing benchtops, sinks, fume hoods, and hallways. Distances of the sampling device locations from the source of dispersion are indicated

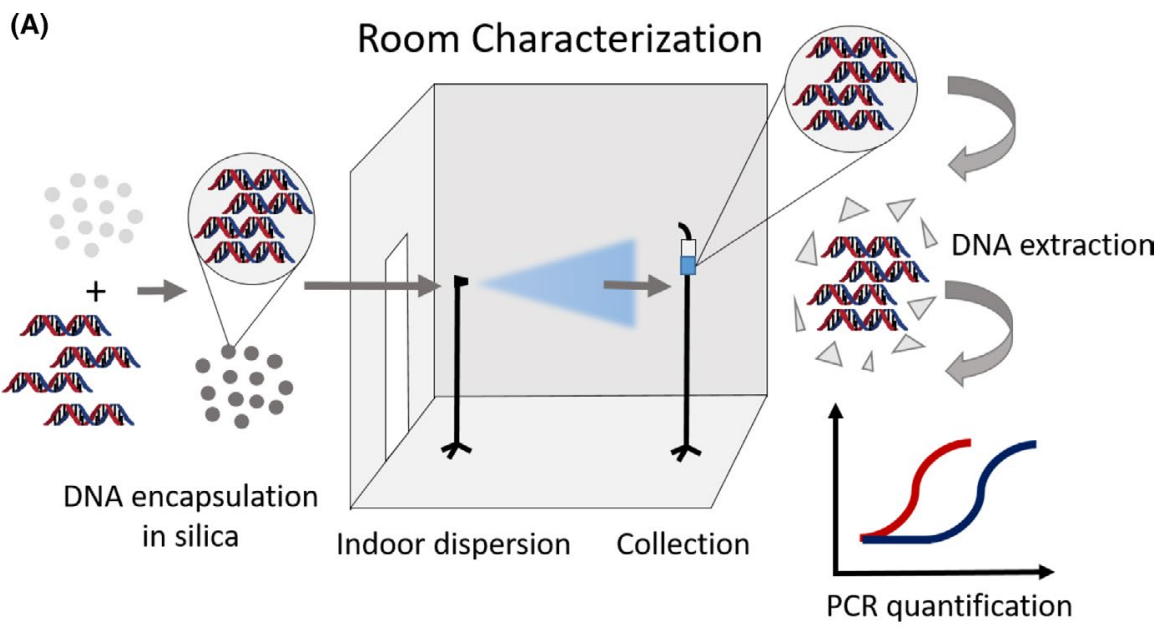

(B)

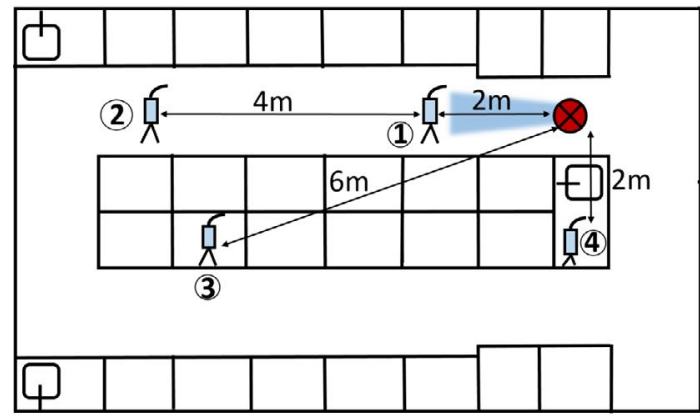

(1)

(3) Sampler (6 m, out of line)

(4) Sampler (2 $\mathrm{m}$, out of line)

(5) Sampler (Atrium, closed door) two locations with a $2 \mathrm{~m}$ offset relative to the airbrush gun's line of flight were sampled simultaneously (labelled positions 3 and 4 in Figure 4B). The results of three separate runs-two with barcode $\mathrm{S} 1$ and one with S2-are displayed in Figure 5B. To relate total load to the distance from the source, the data are always normalized to the $2 \mathrm{~m}$ frontal position, which is standing within the aerosol flow and therefore considered an experimental positive control. The data show that relative exposure is much lower at all three locations that are either further apart from the source or not in the direct line of flight. Additionally, the three experiments qualitatively compare with each other, independent of the DNA barcode used.

In a next step, we wanted to determine the influence of ventilation to aerosol distribution and clearance. We therefore repeated the previous measurements but turned off the ventilation system with doors and windows remaining closed, as before. Figure $5 \mathrm{C}$ compares total load after $2 \mathrm{~h}$ of sampling at the four previous sampling points with ventilation on and off, respectively, again relative to the position close to the point of aerosolization. This experiment revealed a more pronounced concentration difference between the individual sampling points. This result follows intuition, as in the non-ventilated scenario the airflow in the room is more stagnant as opposed to the forced convection found in the experiments under room ventilation.

To assess whether SPED could also be detected in an adjacent room, we placed an additional sampler in the atrium next to the test laboratory (position 5 from Figure 4B), separated by a closed door, with a cubature of $30 \mathrm{~m}^{3}$. These results are displayed separately in Figure 5D, comparing position 5 to position 1 . The expectation was that exposure in the atrium would only be minimal. Interestingly, the exposure is considerable in the ventilated scenario but very low without ventilation. Based on this outcome, we hypothesized that ventilation dynamics could lead to a suction effect from the main room to the atrium. The layout of the ventilation piping (see Appendix S1, Figure S2d), which shows a connection between the two rooms, is compatible with this theory.

As these results were unexpected, we wanted to reconfirm them using another method. We therefore used a fog machine to visualize air dynamics and to add qualitative evidence to the previous results. The fog was generated at the same position as the previous source, and a video camera was installed in the atrium. Indeed, with ventilation running, fog could be visually detected with a delay of ca. 5 min (see Video S1) seemingly coming from the ventilation pipe. The fog does not allow for quantification or localized detection and has a comparatively high detection limit, but it was sufficient to qualitatively confirm our measurements. This shows that the method introduced here is suitable to detect unexpected effects in the distribution dynamics of aerosols in a real-world setting, as caused by a specific ventilation system. There are indications that ventilation systems and air-conditioning can contribute to the spreading of airborne diseases instead of preventing it, ${ }^{10}$ which is why it is already recommended to replace 

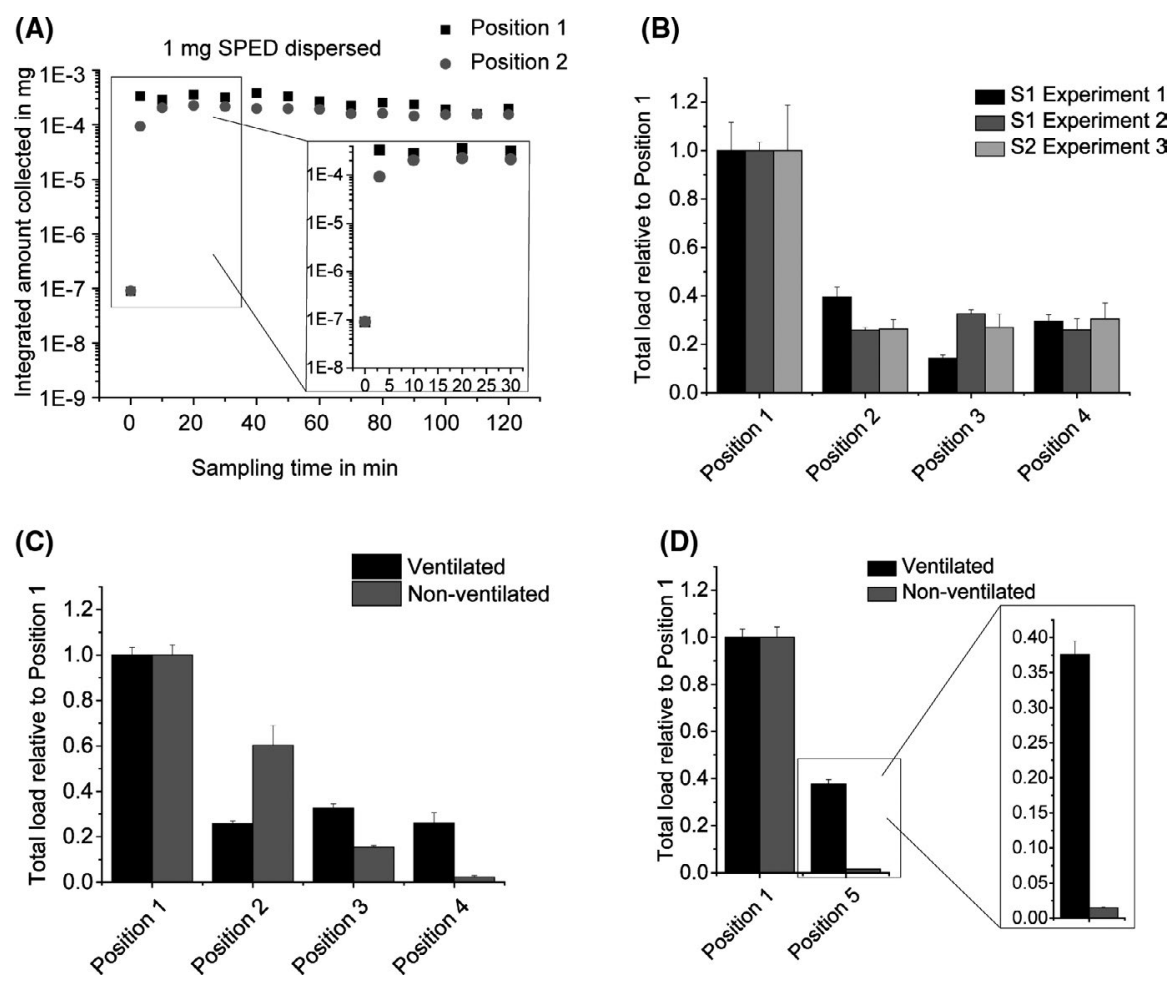

FIGURE 5 Time-, position-, and ventilation-dependent effects as measured by air sampling after dispersion of SPED aerosols. Error bars are calculated from standard deviations of PCR triplicates. Position numbers refer to sampler location in the room as depicted in Figure $4 \mathrm{~b}$. (A) Time-dependent measurement using two air samplers. The y-axis indicates the integrated amount of collected SPED (in mg) over a total time of $120 \mathrm{~min}$. The measurement point at $0 \mathrm{~min}$ was taken immediately before dispersion as a zero control. The first five measurements are zoomed in for clarity. (B) Measurement of position-dependent relative exposure of 4 impingers. Two experiments were performed with particles S1 and a third using particles S2. The values reflect the total amount of particles collected after a 2-h sampling time. The data are normalized to the first position in each set. (C) Total load relative to position 1 per impinger with (data from S1 experiment 2 ) and without ventilation under equal conditions as in (C). (D) Same as (C) but comparing position 1 to an additional position in the adjacent atrium (position 5), which is additionally zoomed in for clarity

air recirculation by increased inflow of outdoor air. ${ }^{71}$ The results show that the described method is able to measure such effects and could, for example, be employed in finding appropriate ventilation settings to limit aerosol spread.

The present proof of concept shows that a simple setup can be used to reliably measure time-, position-, and ventilationdependent relative aerosol loads indoors using different DNA barcodes. Current limitations of the sampling and detection method are a direct result of PCR analysis, which requires normalization to achieve quantitative results. Furthermore, PCR data are logarithmic to the concentration levels. Consequently, result quantification requires a range of control experiments, and small concentration differences are more difficult to detect, requiring numerous sample replicas. Furthermore, the individual measurements were conducted in a real-world environment under similar conditions but without perfect control of external parameters. Factors such as relative humidity, temperature, and the presence and concentration of other particulate matter in the ambient air can influence aerosol dynamics and lead to a difference in absolute aerosol levels accessible to measurement.

Despite the limitations mentioned above, the SPED-based method introduced here has several important benefits, the combination of which makes it novel and unique among aerosol tracers. Important features are the versatility, sensitivity, and specificity toward the sampled barcode and suitability to detect effects related to air circulation. The silica layer protects the DNA from physical and chemical damage, ${ }^{23}$ which is an additional advantage over other DNA-based tracers and makes SPED suitable for indoor and outdoor use alike. The costs of SPED are estimated at $500 \mathrm{USD} / \mathrm{g}$, which benchmarks the price of particles for a single experiment of the scale discussed here at less than 1 USD.

Even though flow impingers were used in this experimental setup, the use of SPED in combination with other means of aerosol capturing is conceivable. This includes surface sampling, even though in past studies ${ }^{37}$ high local SPED concentrations were required for successful swabbing. Furthermore, while the airbrush gun used in this pilot study presents a cost-effective, user-friendly solution, SPED could equally be used in combination with advanced dispersion systems to, for example, more specifically mimic human breathing or coughing. ${ }^{72}$ It has already been shown that SPED detection is possible at a single particle level in solution. ${ }^{27}$ Thus, when limiting barcodes to single use and with a further focus on optimization of the respective sampling and measurement conditions, an additional improvement of the detection 
limit in the range one or two orders of magnitude is conceivable. Consequently, the flexible barcodes offer countless combination possibilities in the future measurements, such as simultaneous surface and air sampling with multiple sources and detectors at extremely low detection limits.

\section{4 | CONCLUSIONS}

In conclusion, this study presents a simple, cost-effective setup for investigating aerosol distribution using a novel tracing agent. The SPED-based platform offers a foundation for a range of real-world tracing scenarios at low detection limits using qPCR as method of analysis. Future applications are the study of aerosol flow in complicated architectural settings and the dynamics of free convection resulting from heating, daytime effects, and door/window arrangements. In the near future, SPED could additionally be tuned in size, made biodegradable, or be designed to mimic specific pathogens or hazardous pollutants. These are ideal prerequisites for developing a robust platform to examine places of interest regarding potential health hazards and environmental risks.

\section{ACKNOWLEDGMENTS}

We thank Prof. Dr. Ulrike Lohmann and Jörg Wieder for supplying us with additional biosampling devices, the group of Prof. Dr. Sotiris Pratsinis for providing support for PDA measurements, and Nikita Kobert for providing the laboratory space and technical support.

\section{CONFLICT OF INTEREST}

The authors declare the following competing financial interest(s): R.N.G. and W.J.S. declare a financial interest in the form of IP on DNA encapsulation licensed to Haelixa AG, of which R.N.G. and W.J.S. are shareholders. A.M.L. and J.K. have no competing financial interests.

\section{PATIENT CONSENT STATEMENT}

No patients were involved in this study or any experiments part of it.

\section{PERMISSION TO REPRODUCE MATERIAL FROM OTHER SOURCES}

No materials from other sources were reproduced.

\section{PEER REVIEW}

The peer review history for this article is available at https://publo ns.com/publon/10.1111/ina.12945.

\section{ORCID}

Anne M. Luescher (D) https://orcid.org/0000-0001-5318-2846

Wendelin J. Stark (D) https://orcid.org/0000-0003-3078-0354

Robert N. Grass (D) https://orcid.org/0000-0001-6968-0823

\section{REFERENCES}

1. Riley RL, Mills C, O'grady F, Sultan L, Wittstadt F, Shivpuri D. Infectiousness of air from a tuberculosis ward: ultraviolet irradiation of infected air: comparative infectiousness of different patients. Am Rev Respir Dis. 1962;85(4):511-525.

2. Riley RL. Airborne infection. Am J Med. 1974;57(3):466-475.

3. Fraser DW. Legionellosis: evidence of airborne transmission. Ann $N$ Y Acad Sci. 1980;353(1):61-66.

4. Moser MR, Bender TR, Margolis HS, Noble GR, Kendal AP, Ritter DG. An outbreak of influenza aboard a commercial airliner. Am J Epidemiol. 1979;110(1):1-6.

5. Sawyer LA, Murphy JJ, Kaplan JE, et al. 25-to 30-nm virus particle associated with a hospital outbreak of acute gastroenteritis with evidence for airborne transmission. Am J Epidemiol. 1988;127(6):1261-1271.

6. Yu IT, Li Y, Wong TW, et al. Evidence of airborne transmission of the severe acute respiratory syndrome virus. N Engl J Med. 2004;350(17):1731-1739.

7. Bourouiba L. Turbulent gas clouds and respiratory pathogen emissions: potential implications for reducing transmission of COVID-19. JAMA. 2020;323(18):1837-1838.

8. Buonanno G, Morawska L, Stabile L. Quantitative assessment of the risk of airborne transmission of SARS-CoV-2 infection: prospective and retrospective applications. Environ Int. 2020;145:106112.

9. Allen JG, Marr LC. Recognizing and controlling airborne transmission of SARS-CoV-2 in indoor environments. Indoor Air. 2020;30(4):557.

10. Correia G, Rodrigues L, Da Silva MG, Gonçalves T. Airborne route and bad use of ventilation systems as non-negligible factors in SARS-CoV-2 transmission. Med Hypotheses. 2020;141:109781.

11. Sørensen DN, Nielsen PV. Quality control of computational fluid dynamics in indoor environments. Indoor Air. 2003;13(1):2-17.

12. Lelieveld J, Helleis F, Borrmann S, et al. Model calculations of aerosol transmission and infection risk of COVID-19 in indoor environments. Int J Environ Res Public Health. 2020;17(21):8114.

13. Knibbs LD, Morawska L, Bell SC, Grzybowski P. Room ventilation and the risk of airborne infection transmission in 3 health care settings within a large teaching hospital. Am J Infect Control. 2011;39(10):866-872.

14. Schade W, Reimer V, Seipenbusch M, Willer U. Experimental investigation of aerosol and CO2 dispersion for evaluation of COVID-19 infection risk in a concert hall. Int J Environ Res Public Health. 2021;18(6):3037.

15. Pyankov OV, Agranovski IE, Pyankova O, et al. Using a bioaerosol personal sampler in combination with real-time PCR analysis for rapid detection of airborne viruses. Environ Microbiol. 2007;9(4):992-1000.

16. Lahd Geagea M, Stille P, Gauthier-Lafaye F, Millet M. Tracing of industrial aerosol sources in an urban environment using $\mathrm{Pb}, \mathrm{Sr}$, and Nd isotopes. Environ Sci Technol. 2008;42(3):692-698.

17. Cahill TA, Barnes DE, Wuest $L$, et al. Artificial ultra-fine aerosol tracers for highway transect studies. Atmos Environ. 2016;136:31-42.

18. McGinn S, Beauchemin K, Iwaasa A, McAllister T. Assessment of the sulfur hexafluoride (SF6) tracer technique for measuring enteric methane emissions from cattle. J Environ Qual. 2006;35(5):1686-1691.

19. Lioy PJ, Vallero D, Foley G, et al. A personal exposure study employing scripted activities and paths in conjunction with atmospheric releases of perfluorocarbon tracers in Manhattan, New York. J Expo Sci Environ Epidemiol. 2007;17(5):409-425.

20. Martin D, Petersson K, Shallcross D. The use of cyclic perfluoroalkanes and SF6 in atmospheric dispersion experiments. $Q J R$ Meteorol Soc. 2011;137(661):2047-2063. 
21. Leighton PA, Perkins WA, Grinnell SW, Webster FX. The fluorescent particle atmospheric tracer. J Appl Meteorol Climatol. 1965;4(3):334-348.

22. Conway TM, Hamilton DS, Shelley RU, et al. Tracing and constraining anthropogenic aerosol iron fluxes to the North Atlantic Ocean using iron isotopes. Nat Commun. 2019;10(1):1-10.

23. Paunescu D, Puddu M, Soellner JO, Stoessel PR, Grass RN. Reversible DNA encapsulation in silica to produce ROSresistant and heat-resistant synthetic DNA 'fossils'. Nat Protoc. 2013;8(12):2440.

24. Croissant JG, Fatieiev Y, Khashab NM. Degradability and clearance of silicon, organosilica, silsesquioxane, silica mixed oxide, and mesoporous silica nanoparticles. Adv Mater. 2017;29(9):1604634.

25. Koch J, Doswald S, Mikutis G, Stark WJ, Grass RN. Ecotoxicological assessment of DNA-tagged silica particles for environmental tracing. Environ Sci Technol. 2021;55(10):6867-6875.

26. Sayes CM, Reed KL, Glover KP, et al. Changing the dose metric for inhalation toxicity studies: short-term study in rats with engineered aerosolized amorphous silica nanoparticles. Inhalation Toxicol. 2010;22(4):348-354.

27. Paunescu D, Mora CA, Querci L, et al. Detecting and number counting of single engineered nanoparticles by digital particle polymerase chain reaction. ACS Nano. 2015;9(10):9564-9572.

28. Wang RF, Cao WW, Cerniglia C. A universal protocol for PCR detection of 13 species of foodborne pathogens in foods. J Appl Microbiol. 1997;83(6):727-736.

29. Guo Z-D, Wang Z-Y, Zhang S-F, et al. Aerosol and surface distribution of severe acute respiratory syndrome coronavirus 2 in hospital wards, Wuhan, China, 2020. Emerg Infect Dis. 2020;26(7):1583-1591.

30. Alvarez AJ, Buttner MP, Stetzenbach LD. PCR for bioaerosol monitoring: sensitivity and environmental interference. Appl Environ Microbiol. 1995;61(10):3639-3644.

31. Agranovski IE, Usachev EV. In-situ rapid bioaerosol detection in the ambient air by miniature multiplex PCR utilizing technique. Atmos Environ. 2021;246:118147.

32. Mikutis G, Deuber CA, Schmid L, et al. Silica-encapsulated DNAbased tracers for aquifer characterization. Environ Sci Technol. 2018;52(21):12142-12152.

33. Mora CA, Schärer H-J, Oberhänsli T, et al. Ultrasensitive quantification of pesticide contamination and drift using silica particles with encapsulated DNA. Environ Sci Technol Lett. 2016;3(1):19-23.

34. Bloch MS, Paunescu D, Stoessel PR, Mora CA, Stark WJ, Grass RN Labeling milk along its production chain with DNA encapsulated in silica. J Agric Food Chem. 2014;62(43):10615-10620.

35. Paunescu D, Stark WJ, Grass RN. Particles with an identity: tracking and tracing in commodity products. Powder Technol. 2016;291:344-350.

36. Mora CA, Paunescu D, Grass RN, Stark WJ. Silica particles with encapsulated DNA as trophic tracers. Mol Ecol Resour. 2015;15(2):231-241.

37. Scotoni M, Koch J, Julian TR, et al. Silica nanoparticles with encapsulated DNA (SPED) - a novel surrogate tracer for microbial transmission in healthcare. Antimicrob Resist Infect Control. 2020;9(1):152.

38. John A, Alhmidi H, Cadnum JL, Jencson AL, Donskey CJ. Contaminated portable equipment is a potential vector for dissemination of pathogens in the intensive care unit. Infect Control Hosp Epidemiol. 2017;38(10):1247-1249.

39. Alhmidi H, Koganti S, Cadnum JL, Jencson AL, John A, Donskey CJ. Dissemination of a nonpathogenic viral DNA surrogate marker from high-touch surfaces in rooms of long-term care facility residents. Am J Infect Control. 2017;45(10):1165-1167.

40. Koganti S, Alhmidi H, Tomas ME, Cadnum JL, Jencson A, Donskey CJ. Evaluation of hospital floors as a potential source of pathogen dissemination using a nonpathogenic virus as a surrogate marker Infect Control Hosp Epidemiol. 2016;37(11):1374-1377.
41. Alhmidi H, John A, Mana TC, et al. Evaluation of viral surrogate markers for study of pathogen dissemination during simulations of patient care. Open Forum Infect Dis. 2017;4(3):ofx128.

42. Alhmidi H, Cadnum JL, Jencson AL, Gweder AA, Donskey CJ. Sharing is not always a good thing: use of a DNA marker to investigate the potential for ward-to-ward dissemination of healthcare-associated pathogens. Infect Control Hosp Epidemiol. 2019;40(2):214-216.

43. Oelberg DG, Joyner SE, Jiang X, Laborde D, Islam MP, Pickering LK. Detection of pathogen transmission in neonatal nurseries using DNA markers as surrogate indicators. Pediatrics. 2000;105(2):311-315.

44. Hermann JR, Zimmerman JJ. Analytical sensitivity of air samplers based on uniform point-source exposure to airborne porcine reproductive and respiratory syndrome virus and swine influenza virus. Can J Vet Res. 2008;72(5):440.

45. Kesavan J, Schepers D, McFarland AR. Sampling and retention efficiencies of batch-type liquid-based bioaerosol samplers. Aerosol Sci Technol. 2010;44(10):817-829.

46. Fabian P, McDevitt J, Houseman E, Milton D. Airborne influenza virus detection with four aerosol samplers using molecular and infectivity assays: considerations for a new infectious virus aerosol sampler. Indoor Air. 2009;19(5):433-441.

47. San Martín C. Latest insights on adenovirus structure and assembly. Viruses. 2012;4(5):847-877.

48. Noda T. Native morphology of influenza virions. Front Microbiol. 2012;2:269.

49. Bar-On YM, Flamholz A, Phillips R, Milo R. SARS-CoV-2 (COVID-19) by the numbers. Elife. 2020;9:e57309.

50. Han ZY, Weng WG, Huang QY. Characterizations of particle size distribution of the droplets exhaled by sneeze. J $R$ Soc Interface. 2013;10(88):20130560.

51. Xie X, Li Y, Sun H, Liu L. Exhaled droplets due to talking and coughing. J R Soc Interface. 2009;6(suppl_6):S703-S714.

52. Duguid J. The numbers and the sites of origin of the droplets expelled during expiratory activities. Edinb Med J. 1945;52(11):385.

53. Duguid J. The size and the duration of air-carriage of respiratory droplets and droplet-nuclei. Epidemiol Infect. 1946;44(6):471-479.

54. Loudon RG, Roberts RM. Droplet expulsion from the respiratory tract. Am Rev Respir Dis. 1967;95(3):435-442.

55. Papineni RS, Rosenthal FS. The size distribution of droplets in the exhaled breath of healthy human subjects. J Aerosol Med. 1997;10(2):105-116.

56. Fennelly KP, Martyny JW, Fulton KE, Orme IM, Cave DM, Heifets LB. Cough-generated aerosols of Mycobacterium tuberculosis: a new method to study infectiousness. Am J Respir Crit Care Med. 2004;169(5):604-609.

57. Yang S, Lee GW, Chen C-M, Wu C-C, Yu K-P. The size and concentration of droplets generated by coughing in human subjects. $J$ Aerosol Med. 2007;20(4):484-494.

58. Johnson GR, Morawska L. The mechanism of breath aerosol formation. J Aerosol Med Pulm Drug Deliv. 2009;22(3):229-237.

59. Jennison MW. Atomizing of mouth and nose secretions into the air as revealed by high-speed photography. Aerobiology. 1942;17:106-128.

60. Fabian P, McDevitt JJ, DeHaan WH, et al. Influenza virus in human exhaled breath: an observational study. PLoS One. 2008;3(7):e2691.

61. Chao CYH, Wan MP, Morawska L, et al. Characterization of expiration air jets and droplet size distributions immediately at the mouth opening. J Aerosol Sci. 2009;40(2):122-133.

62. Fabian P, Brain J, Houseman EA, Gern J, Milton DK. Origin of exhaled breath particles from healthy and human rhinovirus-infected subjects. J Aerosol Med Pulm Drug Deliv. 2011;24(3):137-147.

63. Wells WF. On air-borne infection*: study II. Droplets and droplet nuclei. Am J Epidemiol. 1934;20(3):611-618.

64. Xie X, Li Y, Chwang ATY, Ho PL, Seto WH. How far droplets can move in indoor environments - revisiting the Wells evaporationfalling curve. Indoor Air. 2007;17(3):211-225. 
65. Zuurbier M, Hoek G, Van den Hazel P, Brunekreef B. Minute ventilation of cyclists, car and bus passengers: an experimental study. Environ Health. 2009;8(1):1-10.

66. Willeke K, Lin X, Grinshpun SA. Improved aerosol collection by combined impaction and centrifugal motion. Aerosol Sci Technol. 1998;28(5):439-456.

67. Li J, Leavey A, Wang $\mathrm{Y}$, et al. Comparing the performance of 3 bioaerosol samplers for influenza virus. J Aerosol Sci. 2018;115:133-145.

68. Hogan C Jr, Kettleson E, Lee MH, Ramaswami B, Angenent L, Biswas P. Sampling methodologies and dosage assessment techniques for submicrometre and ultrafine virus aerosol particles. J Appl Microbiol. 2005;99(6):1422-1434.

69. Ji D, Cui Y, Li L, et al. Characterization and source identification of fine particulate matter in urban Beijing during the 2015 Spring Festival. Sci Total Environ. 2018;628:430-440.

70. Samek L, Stegowski Z, Furman L, Styszko K, Szramowiat K, Fiedor J. Quantitative assessment of PM 2.5 sources and their seasonal variation in Krakow. Water Air Soil Pollut. 2017;228(8):1-11.

71. Kurnitski J, Boerstra A, Franchimon F, et al. COVID, REHVA guidance document, April 3, 2020. How to operate and use buildings services in order to prevent the spread of the corona disease (COVID-19) virus (SARS-CoV-2) in workplaces.
72. Lindsley WG, Reynolds JS, Szalajda JV, Noti JD, Beezhold DH. A cough aerosol simulator for the study of disease transmission by human cough-generated aerosols. Aerosol Sci Technol. 2013;47(8):937-944.

73. DB Systemtechnik $\mathrm{GmbH}, \mathrm{K}$. A. u. K. Luftqualität in Schienenfahrzeugen (LUQAS) - Untersuchungen zur Ausbreitungswahrscheinlichkeit von Aerosolen im Fahrgastraum von Schienenfahrzeugen. 2020.

74. van Rijn C, Somsen GA, Hofstra L, et al. Reducing aerosol transmission of SARS-CoV-2 in hospital elevators. Indoor Air. 2020;30(6):1065-1066.

\section{SUPPORTING INFORMATION}

Additional supporting information may be found in the online version of the article at the publisher's website.

How to cite this article: Luescher AM, Koch J, Stark WJ, Grass RN. Silica-encapsulated DNA tracers for measuring aerosol distribution dynamics in real-world settings. Indoor Air. 2022;32:e12945. https://doi.org/10.1111/ina.12945 